\title{
Dependence of the OH concentration on solar UV
}

\author{
Dieter H. Ehhalt and Franz Rohrer \\ Forschungszentrum Jülich GmbH, Institut für Atmosphärische Chemie, Jülich, Germany
}

\begin{abstract}
OH}$ and the major parameters determining its concentration were measured during a field campaign in August 1594 at Mankmoos, a rural, relatively unpolluted site in northeastern Germany. The measured $\mathrm{OH}$ concentrations were previously shown to depend mainly on the intensity of solar UV and on the mixing ratio of $\mathrm{NO}_{2}$. In this paper we develop a simple parameterization of the dependence on solar UV and on $\mathrm{NO}_{2}$. The photolysis of $\mathrm{O}_{3}$ to $\mathrm{O}^{1} D$, of $\mathrm{NO}_{2}$ to $\mathrm{NO}$, and of $\mathrm{HCHO}$ to $\mathrm{HCO}$ and $\mathrm{H}$, all contribute significantly to the total dependence of $\mathrm{OH}$ on solar UV. We demonstrate that the photolysis frequency of $\mathrm{O}_{3}, J_{\mathrm{O}^{1} D}$, is a suitable measure for that dependence which is slightly less than linear. The highly nonlinear dependence of $\mathrm{OH}$ on $\mathrm{NO}_{\mathrm{x}}$ is approximated by a Padé function. The parameterization provides a tool for a future quantitative intercomparison of the measured and modeled dependences of $\mathrm{OH}$ on $\mathrm{UV}$ and $\mathrm{NO}_{2}$. It also allows the removal of the variation in the measured $\mathrm{OH}$ induced by the dependences on the variables, UV and $\mathrm{NO}_{2}$, and thus enables a search for dependences on other, less influential parameters.
\end{abstract}

\section{Introduction}

Atmospheric $\mathrm{OH}$ is primarily produced via the photolysis of $\mathrm{O}_{3}$ by solar ultraviolet radiation (UV) at wavelengths below $340 \mathrm{~nm}$. The resulting excited oxygen atom, $\mathrm{O}^{1} D$, reacts with water molecules to form $\mathrm{OH}$. As a consequence, both measurements and model predictions show a strong diurnal cycle in the tropospheric concentration of $\mathrm{OH}$ with a maximum around local noon and nearly vanishing concentrations at night. In fact, where precise measurements of the ozone photolysis frequency, $J_{\mathrm{O}^{1} D}$, are available, the relation of the measured $\mathrm{OH}$ concentration with the measured $J_{\mathrm{O}^{1} D}$ appears linear within the uncertainties of the measurement in all environments studied so far, reaching from clean marine [Frost et al., 1999] to moderately polluted rural [Ehhalt et al., 1991; Eisele et al., 1997; Holland et al., 1998]. That relation constitutes also the strongest dependence of $\mathrm{OH}$ on any of the parameters influencing it.

Its apparent linearity, however, is not as self-evident as it may seem for several reasons. First, the atmospheric concentration of $\mathrm{OH}$ depends also on other production terms, most of which are also photolytic, such as the photodissociation of $\mathrm{H}_{2} \mathrm{O}_{2}$ or $\mathrm{HCHO}$. In clean surface air these are usually minor; nevertheless, their photolysis frequencies do not vary linearly with $J_{\mathrm{O}^{1} D}$, because these molecules absorb UV at higher wave-

Copyright 2000 by the American Geophysical Union.

Paper number 1999JD901070.

0148-0227/00/1999JD901070\$09.00 lengths [Kraus and Hofzumahaus, 1998]. Second, the destruction of $\mathrm{HO}_{\mathrm{x}}=\mathrm{OH}+\mathrm{HO}_{2}$ includes terms that are quadratic in $\mathrm{HO}_{\mathrm{x}}$, caused by reactions such as $\mathrm{HO}_{2}$ $+\mathrm{HO}_{2} \rightarrow \mathrm{H}_{2} \mathrm{O}_{2}+\mathrm{O}_{2}$. These terms dominate at low concentrations of $\mathrm{NO}_{x}$, where therefore the concentration of $\mathrm{HO}_{\mathrm{x}}$ varies as the square root of the production, i.e., $J_{\mathrm{O}^{1} D}^{1 / 2}$. Finally, $\mathrm{HO}_{2}$ which is generated in the reactions of $\mathrm{OH}$ with trace gas molecules, such as $\mathrm{CO}$ or VOC is recycled to $\mathrm{OH}$ through the reaction $\mathrm{HO}_{2}+$ $\mathrm{NO} \rightarrow \mathrm{OH}+\mathrm{NO}_{2}$. At $\mathrm{NO}_{\mathrm{x}}$ concentrations around 1 ppbv this reaction provides the by far largest positive term in the $\mathrm{OH}$ budget equation [see Ehhalt, 1999]. The concentration of NO depends directly on the photolysis frequency of $\mathrm{NO}_{2}, J_{\mathrm{NO}_{2}}$, whose variation with $J_{\mathrm{O}^{1} D}$ deviates quite strongly from linearity. All these processes could contribute to a nonlinear dependence of $\mathrm{OH}$ on solar UV as represented by the single parameter $J_{O^{1} D}$.

In this communication we evaluate how much $J_{\mathrm{NO}_{2}}$ and $J_{\mathrm{HCHO}_{\mathrm{r}}}$ contribute to the correlation of measured $\mathrm{OH}$ with measured $J_{\mathrm{O}^{1} D}$ and what consequences this contribution has on the linearity of that relation. The final aim is to obtain a simple parametric representation of the dependence of $\mathrm{OH}$ on solar $\mathrm{UV}$ to remove this dominant dependence when searching for others. As it turns out, there is a simple function that parameterizes both the dependence on solar UV as well as that on the $\mathrm{NO}_{2}$ mixing ratio, which is another important influence factor on $\mathrm{OH}$. For a realistic analysis we rely on the data of the POPCORN (Plant Emitted Compounds and $\mathrm{OH}$ Radicals in Northeastern Germany) campaign. It took place in a remote, rural area of northeastern Germany during August 1994 and provided numerous and pre- 
cise measurements of $\mathrm{OH}, \mathrm{NO}_{2}, \mathrm{NO}, J_{\mathrm{O}^{1} D}, J_{\mathrm{NO}_{2}}$, and $J_{\mathrm{HCHO}_{\mathbf{r}}}$ as well as other parameters influencing $\mathrm{OH}$.

\section{Data}

The analysis will be based on the $\mathrm{OH}$ measurements of the LIF instrument during the core time of the POPCORN campaign from August 9 through 23, 1994. Excluding the early morning and late evening data, i.e., the data collected at solar zenith angles $>75^{\circ}$, leaves $2124 \mathrm{OH}$ data points [Holland et al., 1998]. The measurements were made $\sim 4 \mathrm{~m}$ above ground amidst an extended corn field surrounded by slightly rolling meadows and other corn fields. The levels of trace gases interacting with $\mathrm{OH}$ were strongly influenced by this location. The major reactive volatile organic carbon species (VOC) were $\mathrm{HCHO}$ and $\mathrm{CH}_{3} \mathrm{CHO}$ emitted by the drought stressed corn plants. Even the local levels of $\mathrm{NO}_{\mathbf{x}}$ were dominated by emissions from the soil (see below). Because of the remote site, pollution from industrial or vehicular sources remained negligible as evidenced by the low levels of $\mathrm{CO}$ and PAN.

Table 1. Average Trace Gas Mixing Ratios, Photolysis Frequencies and Meteorological Parameters of Influence on the $\mathrm{OH}$ Concentration Along With Their $1 \sigma$ Ranges

\begin{tabular}{lcc}
\hline \multirow{2}{*}{ Parameter } & \multicolumn{2}{c}{ Mixing Ratio, ppbv } \\
\cline { 2 - 3 } & Average & Range \\
\hline & & \\
$\mathrm{O}_{3}$ & 38.7 & 13.7 \\
$\mathrm{NO}$ & 0.44 & 0.51 \\
$\mathrm{NO}_{2}$ & 1.91 & 1.40 \\
$\mathrm{CO}$ & 121 & 26 \\
$\mathrm{CH}$ & $1.9^{*}$ & \\
$\mathrm{HCHO}$ & 1.7 & 0.9 \\
$\mathrm{CH}_{3} \mathrm{CHO}$ & 1.4 & 1.0 \\
$\mathrm{H}_{2} \mathrm{O}_{2}$ & 0.5 & \\
$\mathrm{H}_{2}$ & $550^{*}$ & \\
$\mathrm{PAN}$ & 0.18 & 0.14
\end{tabular}

Photolysis Frequencies, $s^{-1}$

$\begin{array}{lll}\mathrm{O}_{3}+\mathrm{h} \nu \rightarrow \mathrm{O}^{1} D+\mathrm{O}_{2} & 8.0 \times 10^{-6} & 6.6 \times 10^{-6} \\ \mathrm{NO}_{2}+\mathrm{h} \nu \rightarrow \mathrm{NO}+\mathrm{O} & 4.0 \times 10^{-3} & 2.2 \times 10^{-3} \\ \mathrm{HCHO}+\mathrm{h} \nu \rightarrow \mathrm{H}+\mathrm{HCO} & 1.1 \times 10^{-5} & 0.7 \times 10^{-5} \\ \mathrm{H}_{2} \mathrm{O}_{2}+\mathrm{h} \nu \rightarrow 2 \mathrm{OH} & 3.2 \times 10^{-6} & 1.9 \times 10^{-6} \\ \mathrm{CH}_{3} \mathrm{CHO}+\mathrm{h} \nu \rightarrow \mathrm{CH}_{3}+\mathrm{HCO} & 1.1 \times 10^{-6} & 0.8 \times 10^{-6} \\ \mathrm{HONO}+\mathrm{h} \nu \rightarrow \mathrm{OH}+\mathrm{NO} & 7.5 \times 10^{-4} & 4.2 \times 10^{-4}\end{array}$

Meteorological Parameters

$\begin{array}{lcc}\mathrm{P} & 1010 \mathrm{mbar} & 7 \mathrm{mbar} \\ \mathrm{P}\left(\mathrm{H}_{2} \mathrm{O}\right) & 14.2 \mathrm{mbar} & 2.6 \mathrm{mbar} \\ \mathrm{T} & 293 \mathrm{~K} & 4.5 \mathrm{~K}\end{array}$

Data from Kraus and Hofzumahaus [1998], Rohrer et al. [1998], Koppmann et al. [1998], Schrimpf et al. [1998], and Benning and Wahner [1998].

*Not regularly measured.

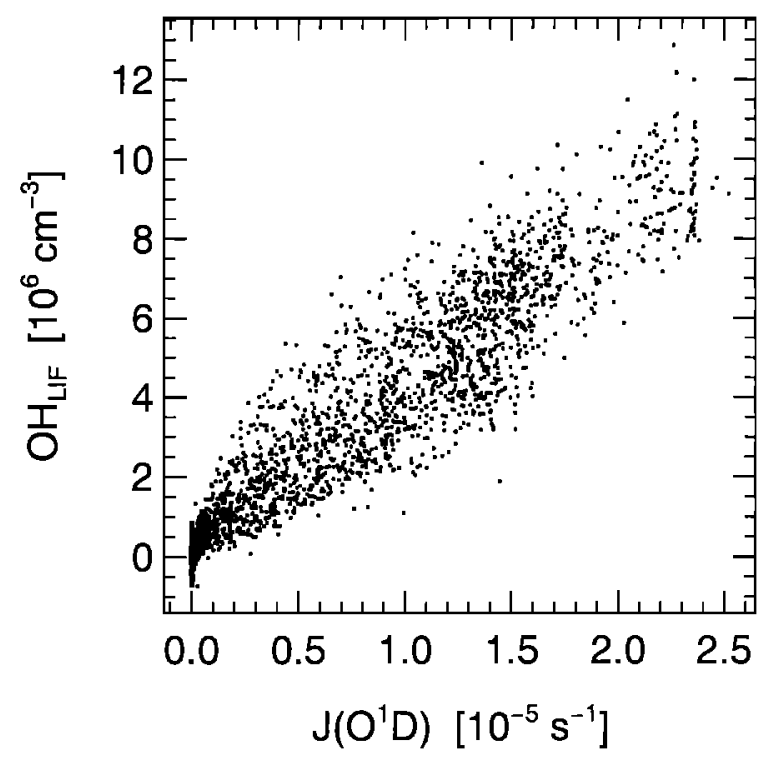

Figure 1. Correlation plot of the $\mathrm{OH}$ concentration measured by laser induced fluorescence [Holland et al., 1998] and the measured photolysis frequency of $\mathrm{O}_{3}$ [Kraus and Hofzumahaus, 1998] during the POPCORN campaign, August 1994. The correlation coefficient is $R=0.924$; the linear regression slope is $(3.94 \pm 0.04) \times$ $10^{11} \mathrm{~s} \mathrm{~cm}^{-3}$.

The average values of the measured auxiliary parameters and their $1 \sigma$ ranges during that period are listed in Table 1. It also includes references describing the data in detail, as well as measurement techniques and their precision.

The correlation between the measured $\mathrm{OH}$ concentration and the measured $J_{\mathrm{O}^{1} D}$ is shown in Figure 1. It also appears to be very close to linear. A linear regression analysis yields a slope of $(3.94 \pm 0.035) \times 10^{11} \mathrm{~s} \mathrm{~cm}^{-3}$ and an offset of $(0.409 \pm 0.038) \times 10^{6} \mathrm{~cm}^{-3}$. The correlation coefficient $R=0.924$. In a probabilistic sense, $R^{2}=0.85$ can be interpreted as the fraction of the total variation in $\mathrm{OH}$ which can be explained by the linear regression between $\mathrm{OH}$ and $J_{\mathrm{O}^{1} D}$. This means that $85 \%$ of the total variation in $\mathrm{OH}$ is explained by the variation in solar UV, but not as Figure 1 might suggest by that of $J_{\mathrm{O}^{1} D}$ alone. Together with $J_{\mathrm{O}^{1} D}$, all other photolysis frequencies vary also and thus contribute to the slope of the regression line. $J_{\mathrm{O}^{1} D}$ is merely a convenient measure for the dependence on solar UV, since it provides by far the largest individual influence. The $1 \sigma$-measurement error of $\mathrm{OH}$, which averages $0.5 \times 10^{6} \mathrm{~cm}^{-3}$ [Holland et al., 1998], contributes $9 \%$ to the observed total variation in $\mathrm{OH}$. The rest is due to the dependence of $\mathrm{OH}$ on other trace gases which varied during the duration of the campaign (see Table 1).

\section{Discussion}

Besides $J_{\mathrm{O}^{1} D}$ the $\mathrm{OH}$ data obtained during POPCORN also depend significantly on the mixing ratio of 


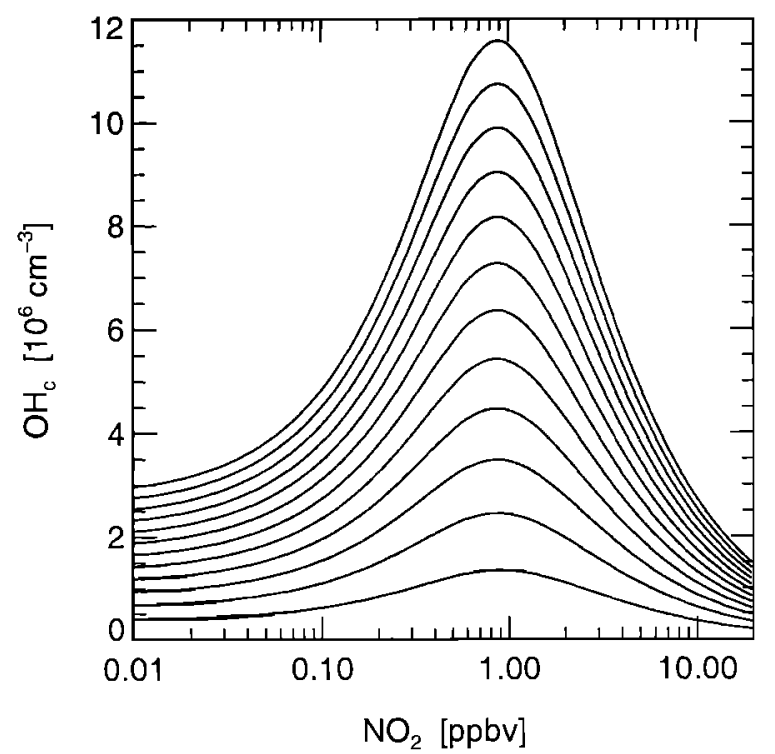

Figure 2. Dependence of the $\mathrm{OH}$ concentration on the $\mathrm{NO}_{2}$ mixing ratio for values of $J_{\mathrm{O}^{1} D}$ increasing in steps of $2 \times 10^{-6} \mathrm{~s}^{-1}$ from a starting value of $2 \times 10^{-6} \mathrm{~s}^{-1}$. The curves are calculated by a box model for the mean conditions of the POPCORN campaign (see text).

$\mathrm{NO}_{\mathrm{x}}$ [see Ehhalt, 1999, Figure 2.44]. The measured dependence exhibits the typical highly nonlinear behavior with a maximum of $\mathrm{OH}$ at a $\mathrm{NO}_{\mathrm{x}}$ mixing ratio of $\sim 1.5$ $\mathrm{ppbV}$. This type of dependence is illustrated in more detail by Figure 2, which shows the model predicted dependence of $\mathrm{OH}$ on $\mathrm{NO}_{2}$ for various $J_{\mathrm{O}^{1} D}$. The curves were calculated from a box model with a chemical reaction system appropriate for the trace gases listed in Table 1 . VOC other than $\mathrm{CH}_{3} \mathrm{CHO}$ and $\mathrm{HCHO}$ were neglected. On average their total effect on $\mathrm{OH}$ was slightly less than that of $\mathrm{CH}_{3} \mathrm{CHO}$ alone. We used the rate constants recommended by DeMore et al. [1997] and the mean mixing ratios given in Table 1, except of course for $\mathrm{NO}_{\mathrm{x}}$, and assumed steady state conditions. Because of the surface source of $\mathrm{NO}$, measured $\mathrm{NO}$ and $\mathrm{NO}_{2}$ deviated from the photochemical steady state to a variable extent. For consistency in the model calculations we adopted $\mathrm{NO}_{2}$ as independent variable and derived $\mathrm{NO}$ from it. The various photolysis frequencies were linked to $J_{\mathrm{O}^{1} D}$ by empirical relations derived from the POPCORN measurements (Kraus and Hofzumahaus [1998]; see eq.(3)). Thus, as in the field observations, all photolysis frequencies vary with $J_{\mathrm{O}^{1} D}$. The model, incidentally, reproduces the measured $\mathrm{OH}$ concentrations quite well. A scatterplot of calculated versus measured $\mathrm{OH}$ clusters closely around a straight line with a slope of $1.08 \pm 0.05$, indicating a barely significant overprediction by the model of $\sim 10 \%$ [see Ehhalt, 1999, Figure 2.45].

The curves in Figure 2 demonstrate the typical, highly nonlinear dependence of $\mathrm{OH}$ on $\mathrm{NO}_{2}$. Moreover, they show that the dependence of $\mathrm{OH}$ on $J_{\mathrm{O}^{1} D}$ is also a function of the $\mathrm{NO}_{2}$ concentration. Since $\mathrm{NO}_{\mathbf{x}}$ and $J_{\mathrm{O}^{1} D}$ vary independently, the spread in observed $\mathrm{NO}_{2}$ must contribute to the scatter in Figure 1. It may, in fact, obscure the correlation between $\mathrm{OH}$ and $J_{\mathrm{O}^{1} D}$ in conditions with a large range in $\mathrm{NO}_{\mathbf{x}}$, but a small one in $J_{\mathrm{O}^{1} D}$, such as on a cloudy day. It seems useful therefore to find a formulation that quantifies the $\mathrm{OH}$ dependence on $J_{\mathrm{O}^{1} D}$ and $\mathrm{NO}_{2}$ at the same time. Such formulations exist for small $\mathrm{NO}_{2}$ and large $\mathrm{NO}_{2}$, i.e. either for the far left or the far right flank of the curves in Figure 2. There, simple physical approximations become feasible, because in each case the $\mathrm{HO}_{\mathrm{x}}$ loss is dominated by a single type of reaction - the reaction of $\mathrm{HO}_{2}$ with $\mathrm{RO}_{2}$ in the first case and $\mathrm{OH}$ with $\mathrm{NO}_{2}$ in the second [Sillman et al., 1990]. However, so far there is no simple formulation to cover the central part of these curves, which is determined by the most complex and interesting chemistry and where many of the existing measurements have been made.

The fact that the curves in Figure 2 have the same functional form, along with their asymptotic behavior, which for $\mathrm{NO}_{2} \rightarrow 0$ is independent of $\mathrm{NO}_{2}$ and for $\mathrm{NO}_{2} \rightarrow \infty$ varies as $1 / \mathrm{NO}_{2}$, suggests a parameterization of the type

$$
[\mathrm{OH}]=a\left(J_{\mathrm{O}^{1} D}\right)^{\alpha} \frac{b \mathrm{NO}_{2}+1}{c \mathrm{NO}_{2}{ }^{2}+d \mathrm{NO}_{2}+1}
$$

Equation (1) is a so-called Padé approximation in $\mathrm{NO}_{2}$ [Harris and Stocker, 1998]. It at the same time parameterizes the dependence of $\mathrm{OH}$ on $\mathrm{NO}_{2}$ and $J_{\mathrm{O}^{1} D}$, where $J_{\mathrm{O}^{1} D}$ is still representative of the influence of all photolysis frequencies and where $\mathrm{NO}_{2}$ can vary over all possible values. Equation (1) is not based on a physical concept but rather represents a simple function describing the curves in Figure 2. It separates the dependences into two simple factors and demonstrates that the slope of $\mathrm{OH}$ versus $J_{\mathrm{O}^{1} D}$ also depends on the mixing ratio of $\mathrm{NO}_{2}$. A fit of (1) to all the model calculated curves in Figure 2 yields $\alpha_{c}=0.85$, where the index $c$ denotes the fit to the calculated $\mathrm{OH}$. Obviously, the dependence of $\mathrm{OH}$ on $J_{\mathrm{O}^{1} D}$ is slightly less than linear, which is also indicated by the closer spacing of the curves at higher $J_{\mathrm{O}^{1} D}$ in Figure 2. The fitted values of the other constants in (1) are the following: $a_{c}=2.36 \times 10^{10}, b_{c}=$ $8.7, c_{c}=0.9, d_{c}=0.51$ when $\mathrm{OH}$ is measured in $\mathrm{cm}^{-3}$, $\mathrm{NO}_{2}$ in ppbv, and $J_{\mathrm{O}^{1} D}$ in s $\mathrm{s}^{-1}$. The correlation coefficient $R_{c}=0.999$, the standard deviation between the model calculated $\mathrm{OH}$ and $\mathrm{OH}$ approximated by (1), is $0.07 \times 10^{6} \mathrm{~cm}^{-3}$, i.e., the fit of the model calculated $\mathrm{OH}$ by eq.(1) is excellent. At this point the physical meaning of the coefficients $a_{c} \ldots d_{c}$ has not been determined. However, they must depend on the other variables that influence $\mathrm{OH}$, such as the concentration of $\mathrm{H}_{2} \mathrm{O}, \mathrm{CO}$, or VOC, which were kept constant in the model. We also note that the numerical value of $\alpha_{c}$ must to some extent depend on the choice of $\mathrm{NO}_{2}$ rather than $\mathrm{NO}_{\mathrm{x}}$ as independent variable. 


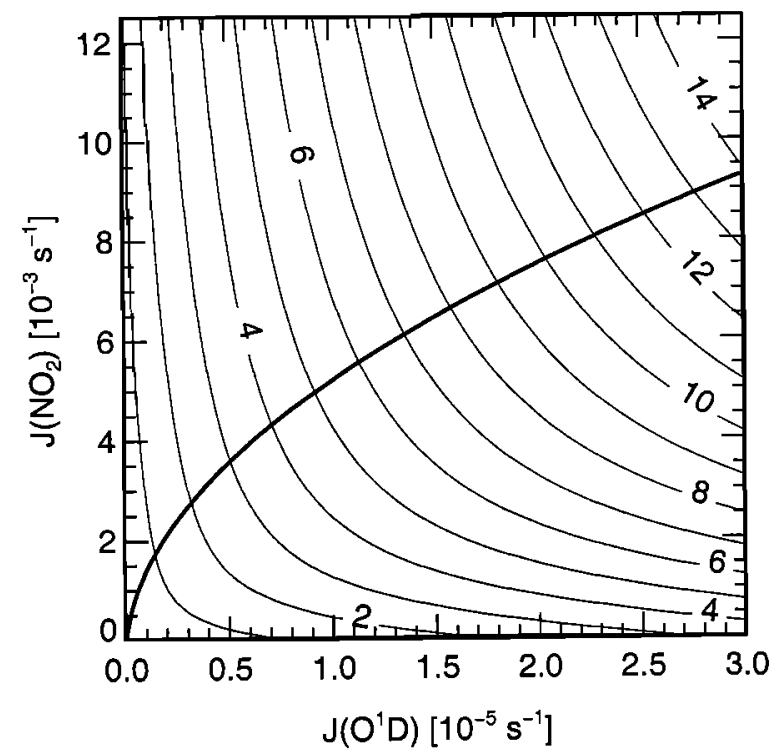

Figure 3. Model calculated dependence of the $\mathrm{OH}$ concentration on $J_{\mathrm{O}^{1} D}$ and $J_{\mathrm{NO}_{2}}$ for a $\mathrm{NO}_{2}$ mixing ratio of 1 ppbv. The isolines of constant $\mathrm{OH}$ concentration (thin curves) are given in units of $10^{6} \mathrm{~cm}^{-3}$. The heavy curve indicates the average relation of measured $J_{\mathrm{NO}_{2}}$ and $J_{\mathrm{O}^{1} D}$ (see equation $(3)$ in text).

Equation (1) also approximates the measured $\mathrm{OH}$ concentrations given in Figure 1 quite well. A fit yields the coefficients: $\alpha_{m}=0.91, a_{m}=2.5 \times 10^{9}, b_{m}=189$, $c_{m}=0.44$, and $d_{m}=1.32$, whele the index $m$ denotes the fit to the measured $\mathrm{OH}, \mathrm{NO}_{2}$, and $J_{\mathrm{O}^{1} D}$. Thus, although hard to detect by eye, the measured $\mathrm{OH}$ also depends less than linearly on $J_{\mathrm{O}^{1} D}$. The correlation coefficient between measured $\mathrm{OH}$ and that calculated from (1) from measured $J_{\mathrm{O}^{1} D}$ and $\mathrm{NO}_{2}$ is 0.929 . Inclusion of the dependence on $\mathrm{NO}_{2}$ and of the nonlinear dependence on $J_{\mathrm{O}^{1} D}$ explains $86 \%$ of the variation in the measured $\mathrm{OH}$. The standard deviation between measured $\mathrm{OH}$ and that calculated from (1), is $1 \times 10^{6} \mathrm{~cm}^{-3}$.

The model calculations also allow to separate the dependence of $\mathrm{OH}$ on $J_{\mathrm{NO}_{2}}$ from that on $J_{\mathrm{O}^{1} D}$. The results are shown in Figure 3. It is based on the same conditions as used for Figure 2 except that the $\mathrm{NO}_{2}$ mixing ratio is fixed at $1 \mathrm{ppbv}$, close to the maximum impact of $\mathrm{NO}_{\mathbf{x}}$ (see Figure 2) and that $J_{\mathrm{NO}_{2}}$ and $J_{\mathrm{O}^{1} D}$ are allowed to vary independently of each other. The other photolysis frequencies are described by the same empirical relations as before and thus still are represented by $J_{\mathrm{O}^{1} D}$.

The curvature of the $\mathrm{OH}$ isolines in Figure 3 clearly demonstrates that for $\mathrm{NO}_{2}=1 \mathrm{ppbv} \mathrm{OH}$ depends on both, $J_{\mathrm{NO}_{2}}$ and $J_{\mathrm{O}^{1} D}$. The partial derivatives $\partial \mathrm{OH} / \partial J_{\mathrm{O}^{1} D}$ and $\partial \mathrm{OH} / \partial J_{\mathrm{NO}_{2}}$ can be read from Figure 3 . Because of the concave form of the isolines both partial derivatives become smaller with higher $J$; i.e., the dependences of $\mathrm{OH}$ on $J_{\mathrm{O}^{1} D}$ and even more so that on $J_{\mathrm{NO}_{2}}$ are significantly less than linear. From the par- tial derivatives we can also calculate the contribution of $J_{\mathrm{NO}_{2}}$ to the slope, $d \mathrm{OH} / d J_{\mathrm{O}^{1} D}$, in Figure 1. It is given by the second term in (2):

$$
\frac{d \mathrm{OH}}{d J_{\mathrm{O}^{1} D}}=\frac{\partial \mathrm{OH}}{\partial J_{\mathrm{O}^{1} D}}+\frac{\partial \mathrm{OH}}{\partial J_{\mathrm{NO}_{2}}} \frac{d J_{\mathrm{NO}_{2}}}{d J_{\mathrm{O}^{1} D}}
$$

The empirical relation (3) established for the POPCORN data and shown as heavy line in Figure 3

$$
J_{\mathrm{NO}_{2}}=1.61\left(J_{\mathrm{O}^{1} D}\right)^{1 / 2}
$$

can be used to calculate $d J_{\mathrm{NO}_{2}} / d J_{\mathrm{O}^{1} D}$. As an example, we solve (2) for the averages of $J_{\mathrm{NO}_{2}}$ and $J_{\mathrm{O}^{1} D}$ during the POPCORN campaign, $4.0 \times 10^{-3} \mathrm{~s}^{-1}$ and $8.0 \times$ $10^{-6} \mathrm{~s}^{-1}$ respectively. At that point, $\partial \mathrm{OH} / \partial J_{\mathrm{NO}_{2}}=$ $3.9 \times 10^{8} \mathrm{~cm}^{-3} \mathrm{~s}, \partial \mathrm{OH} / \partial J_{\mathrm{O}^{1} D}=3.6 \times 10^{11} \mathrm{~cm}^{-3} \mathrm{~s}$, and $d J_{\mathrm{NO}_{2}} / d J_{\mathrm{O}^{1} D}=285$. We note that for the present example the contribution by $J_{\mathrm{NO}_{2}}$ amounts to $1.1 \times$ $10^{11} \mathrm{~cm}^{-3} \mathrm{~s}$, which is $1 / 3$ of that of $J_{\mathrm{O}^{1} D}$ proper or $1 / 4$ of that of the total slope $d \mathrm{OH} / d J_{\mathrm{O}^{1} D}=4.7 \times 10^{11} \mathrm{~cm}^{-3} \mathrm{~s}$. The latter being derived for $\mathrm{NO}_{2}=1 \mathrm{ppbv}$, the $\mathrm{NO}_{2}$ mixing ratio of maximum impact on $\mathrm{OH}$, is slightly larger than the slope found from Figure 1, which is rather applicable for the average $\mathrm{NO}_{2}$ mixing ratio of 1.9 ppbv.

Figure 3 also demonstrates a nearly equidistant spacing between the intersections of the $\mathrm{OH}$ isolines and the curve for (3). Above a $J_{\mathrm{O}^{1} D}$ value of $0.5 \times 10^{-5} \mathrm{~s}^{-1}$ this transforms into a nearly equidistant spacing along the $J_{\mathrm{O}^{1} D}$ axis and indicates that the partial nonlinear dependences of $\mathrm{OH}$ on $J_{\mathrm{O}^{1} D}$ and $J_{\mathrm{NO}_{2}}$ superimpose in such a way that the total correlation of $\mathrm{OH}$ with $J_{\mathrm{O}^{1} D}$ is very nearly linear, just as observed directly in Figure 1. This is actually true over a wide range of $\mathrm{NO}_{2}$ mixing ratios. We also note that the isolines of constant $\mathrm{OH}$ strongly depend on the $\mathrm{NO}_{2}$ mixing ratio chosen. For a $\mathrm{NO}_{2}$ mixing ratio of $5 \mathrm{ppbv}$ they would run essentially parallel to the $J_{\mathrm{NO}_{2}}$ axis except for very low $J_{\mathrm{NO}_{2}}$ values; i.e., in that case, $\mathrm{OH}$ is essentially independent of $J_{\mathrm{NO}_{2}}$.

In fact, all contributions of the various photolysis processes to $\mathrm{OH}$ vary with $\mathrm{NO}_{2}$. This is shown in Figure 4, which presents a breakdown for the most important photolysis frequencies, namely $J_{\mathrm{O}^{1} D}, J_{\mathrm{NO}_{2}}$, and $J_{\mathrm{HCHO}_{\mathrm{r}}}$. The individual contributions were calculated analogous to the separation of $\mathrm{N}_{\mathrm{NO}_{2}}$ in (2) for the average mixing ratios and photolysis frequencies given in Table 1.

Figure 4a shows the absolute contribution to the total slope, which is also shown and presents the sum of the specified and all other contributions by photolysis processes. The latter amount to $<5 \%$ of the total for the conditions during POPCORN, whereas the photolysis of $\mathrm{NO}_{2}$ and HCHO make sizable contributions to a dominant $J_{\mathrm{O}^{1} D}$ proper for all $\mathrm{NO}_{2}$ mixing ratios encountered during POPCORN.

Figure $4 \mathrm{~b}$ presents the corresponding sensitivities, $\partial \ln (\mathrm{OH}) / \partial \ln (J) \cdot d \ln (J) / d \ln \left(\mathrm{J}_{\mathrm{O}^{1} \mathrm{D}}\right)$; they are equivalent to the respective contributions to the exponent $\alpha$ 


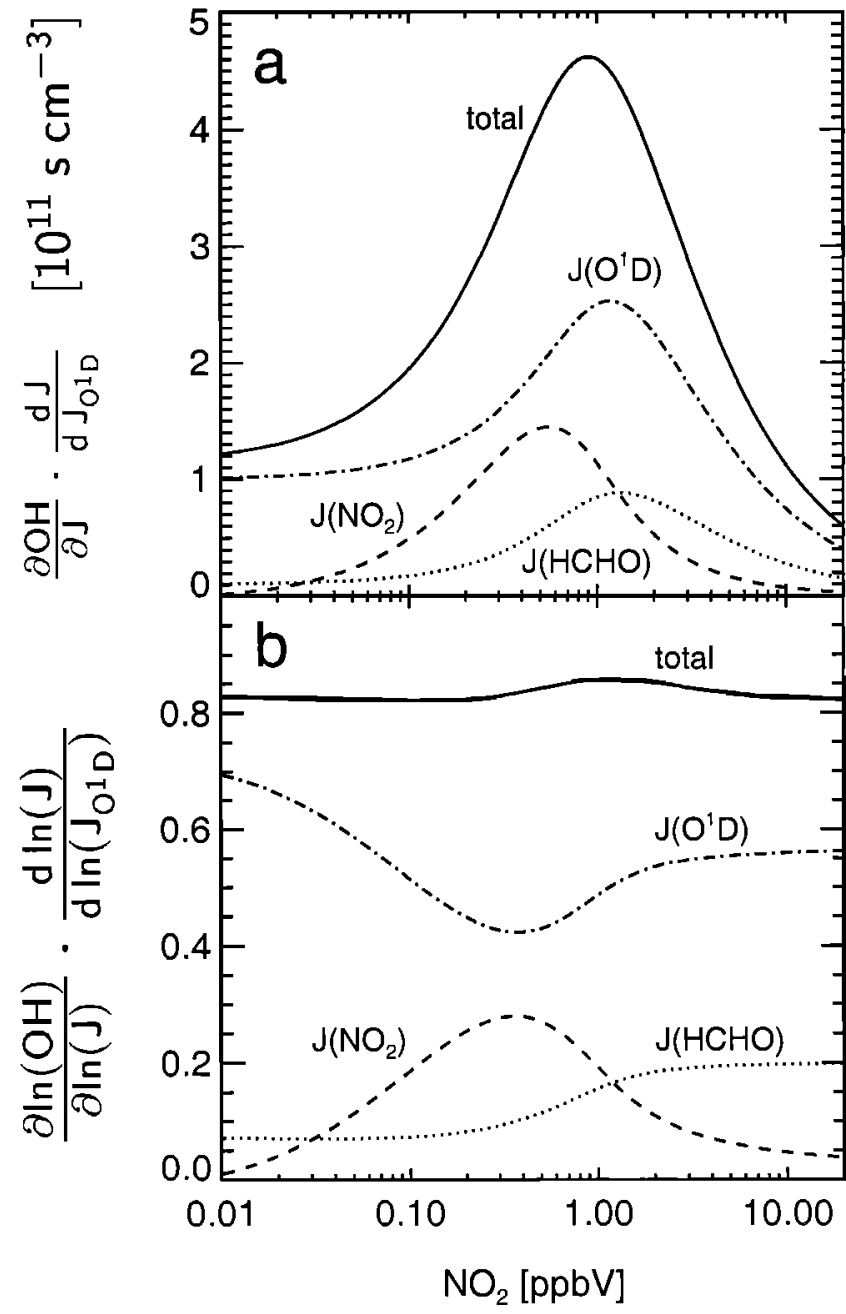

Figure 4. (a) Contributions by $J_{\mathrm{O}^{1} D}, \quad J_{\mathrm{NO}_{2}}$, and $J_{\mathrm{HCHO}_{r}}$ to the dependence of $\mathrm{OH}$ on solar UV for the mean conditions specified in Table 1, and (b) the corresponding sensitivities $\partial \ln (\mathrm{OH}) / \partial \ln (\mathrm{J})\left[d \ln (\mathrm{J}) / d \ln \left(\mathrm{J}_{\mathrm{O}^{1} \mathrm{D}}\right)\right]$. The respective totals are also given.

in (1). The individual sensitivities all vary significantly with $\mathrm{NO}_{2}$, each in a different manner. Nevertheless, their sum, i.e., the exponent $\alpha$ in (1), remains nearly constant with $\mathrm{NO}_{2}$ around an average of 0.85 . In retrospect this provides a justification for the fact that in (1) we were able to lump the dependence on the different photolysis processes into a single parameter, $J_{\mathrm{O}^{1} D}$.

For completeness we mention that the measured individual $J_{\mathrm{NO}_{2}}$ values have also a component that varies independently of $J_{\mathrm{O}^{1} D}$, because $J_{\mathrm{NO}_{2}}$ and $J_{\mathrm{O}^{1} D}$ depend differently on the actual stratospheric $\mathrm{O}_{3}$ column and the actual degree of cloudiness. As a consequence, the individual $J_{\mathrm{NO}_{2}}$ values scatter considerably, more than a factor of 1.2 , around the average defined by (3) [cf. Kraus and Hofzumahaus, 1998, Figure 4]. This should result in an explicit dependence of $\mathrm{OH}$ on $\mathrm{J}_{\mathrm{NO}_{2}}$, even when the mean dependence of $J_{\mathrm{NO}_{2}}$ on $J_{\mathrm{O}^{1} D}$ is accounted for. Such a dependence is indeed present, both in the modeled and measured $\mathrm{OH}$ concentrations, and shown in Figure 5. To make it clearly visible, the dependences of $\mathrm{OH}$ on solar UV and the $\mathrm{NO}_{2}$ mixing ratio have been removed by subtracting from each individual $\mathrm{OH}$ data point the corresponding $\mathrm{OH}$ value calculated from (1) either for the modeled or measured data, respectively. The individual $J_{\mathrm{NO}_{2}}$ is referenced to relation (3) to remove its mean dependence on $J_{\mathrm{O}^{1} D}$. These differences are then normalized such that the slope of these plots yields directly the sensitivity. The data points with $J_{\mathrm{NO}_{2}}<10^{-4} \mathrm{~s}^{-1}$ are omitted to limit the spread of the normalized $J_{\mathrm{NO}_{2}}$. The box model

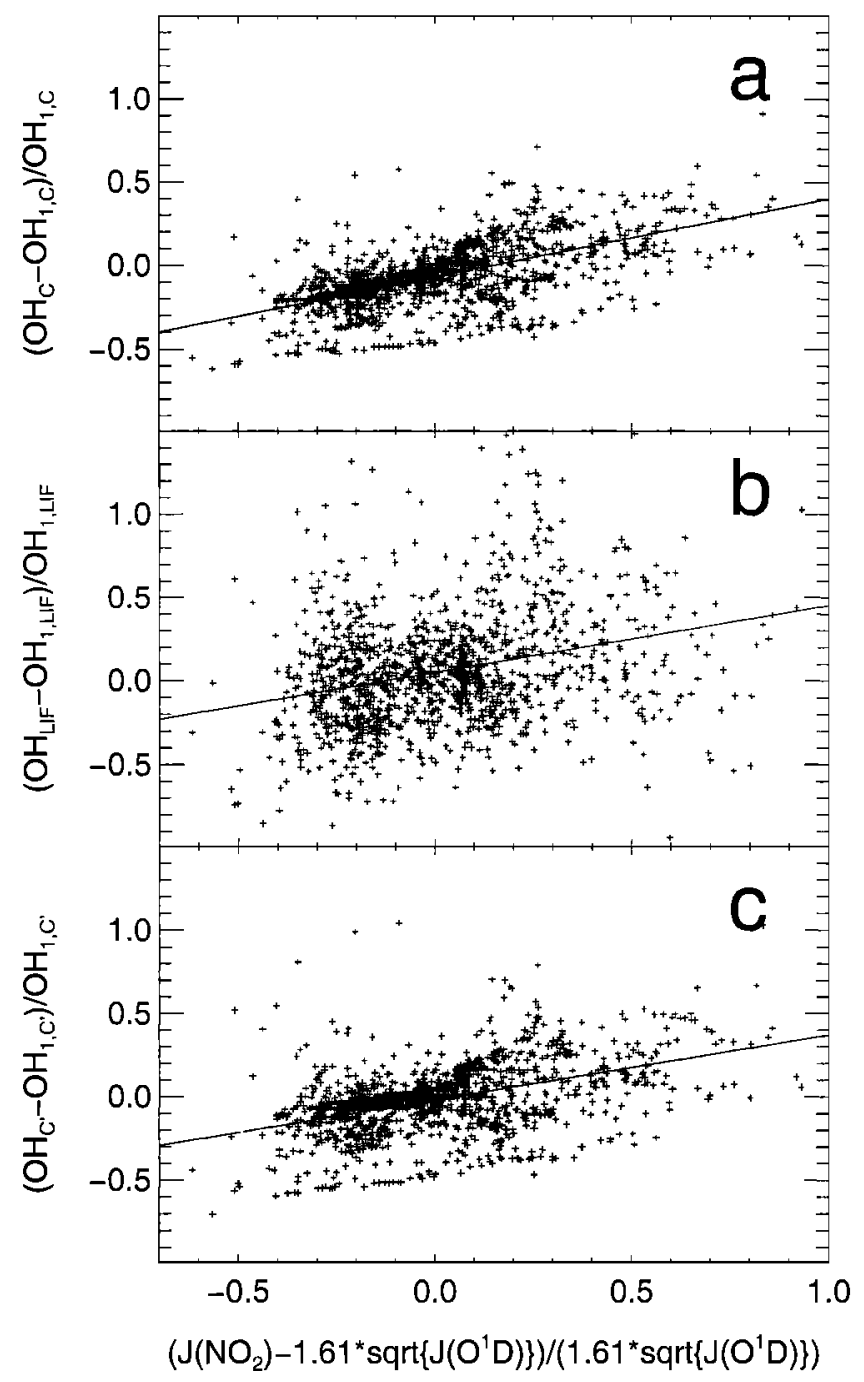

Figure 5. Correlation of normalized $\mathrm{OH}$ and normalized $J_{\mathrm{NO}_{2}}$. The normalization serves to remove the dependence of $\mathrm{OH}$ on $J_{\mathrm{O}^{1} D}$ and on the $\mathrm{NO}_{2}$ mixing ratio; for $J_{\mathrm{NO}_{2}}$ that on $J_{\mathrm{O}^{1} D}$ (see text): (a) Individual $\mathrm{OH}$ values calculated by a box model from the auxiliary measurements; (b) corresponding measured $\mathrm{OH}$ concentrations; (c) same as Figure 5a except the inclusion of a local NO input of $4.2 \times 10^{7} \mathrm{~cm}^{-3} \mathrm{~s}^{-1}$. The linear regression lines fitted to the data are also shown. Their slopes are $0.47 \pm 0.02$ (Figure 5a), $0.40 \pm 0.04$ (Figure 5b), and $0.39 \pm 0.02$ (Figure $5 \mathrm{c}$ ). 
data (Figure 5a) yield a slope of $0.47 \pm 0.02$, which suggests that $\mathrm{OH}$ varies as $\left(\mathrm{NO}_{2}\right)^{1 / 2}$. The measured $\mathrm{OH}$ shows a much larger scatter, which is to be expected, but also a slightly smaller slope of $0.40 \pm 0.04$. This small difference is probably real and caused by the relatively strong surface source of NO observed during the POPCORN campaign with a strength of $1.8 \times 10^{11}$ molecules cm $\mathrm{cm}^{-2} \mathrm{~s}^{-1}$ [Rohrer et al., 1998]. This causes a net transport of NO molecules into the observed air volume at $\sim 4 \mathrm{~m}$ height, which does not depend on $\mathrm{NO}_{2}$ photolysis and thus reduces the relative influence of $J_{\mathrm{NO}_{2}}$ on $\mathrm{OH}$. The effect of the added $\mathrm{NO}$ is demonstrated by a box model calculation which includes an NO input of $4.2 \times 10^{7} \mathrm{~cm}^{-3} \mathrm{~s}^{-1}$ (Figure $5 \mathrm{c}$ ). That input corresponds to the vertical NO flux divergence at 4-m height as calculated from a 1-D model and the above surface source (F. Rohrer et al., 1999, manuscript in preparation). It results in a slope of $0.39 \pm 0.02$ in good agreement with the slope in Figure $5 \mathrm{~b}$. In the present case this is most probably the full explanation for the difference between the slopes in Figure 5a and $5 \mathrm{~b}$. In general, however, any process that acts as $\mathrm{OH}$ source but is independent of $J_{\mathrm{NO}_{2}}$, such as the reaction of alkenes with $\mathrm{O}_{3}$, will have a similar effect on the slopes in Figure 5 and may cause the modeled slope (Figure 5a) to deviate from that measured (Figure $5 \mathrm{~b}$ ), if not fully accounted for by the model.

In any case these findings suggest that $J_{\mathrm{NO}_{2}}$ should be included separately into (1) to reach an even more realistic parameterization of the measured $\mathrm{OH}$, i.e.,

$$
[\mathrm{OH}]=a\left(J_{\mathrm{O}^{1} D}\right)^{\alpha}\left(J_{\mathrm{NO}_{2}}\right)^{\beta} \frac{b \mathrm{NO}_{2}+1}{c \mathrm{NO}_{2}^{2}+d \mathrm{NO}_{2}+1}
$$

The parameters obtained by a fit to the full set of 2124 measurements are $\alpha=0.83, \beta=0.19, a=$ $4.1 \times 10^{9}, b=140, c=0.41$, and $d=1.7$, indicating a strong, slightly nonlinear dependence of $\mathrm{OH}$ on $J_{\mathrm{O}^{1} D}$ and a small but highly nonlinear contribution from $J_{\mathrm{NO}_{2}}$. Equation (4) will be used to remove the dependences of $\mathrm{OH}$ on $J$ and $\mathrm{NO}_{2}$ in our future attempts to extract dependences on other variables from the POPCORN data set.

The correlation coefficient between the measured $\mathrm{OH}$ values and the one derived from (4) is 0.932 , barely larger than the one derived from the linear fit in Figure 1. Apparently, even the simpler parameterizations provide a good account of the variation in $\mathrm{OH}$ caused by solar UV. How good an account is, of course, also a function of the precision in the measurements especially that of $\mathrm{OH}$, which by itself places an upper limit of 0.955 on the attainable correlation coefficient. The correlation coefficient achievable by (4) depends also on the ranges of the other variables influencing $\mathrm{OH}$, which happened to be small during POPCORN. Because of the latter (4) is also quite a good predictor for the measured $\mathrm{OH}$ during POPCORN: the mean standard de- viation of the so predicted $\mathrm{OH}$ from that measured is $0.98 \times 10^{6} \mathrm{~cm}^{-3}$, hardly bigger than $0.95 \times 10^{6} \mathrm{~cm}^{-3}$ the standard deviation of the measured $\mathrm{OH}$ values from those calculated with a full model.

Because of the general applicability of the Pade approximation the functions defined by (4) or (1) should be rather universally applicable and useful for the analysis of the $\mathrm{OH}$ dependences in other environments as well. The values of the coefficients derived here, however, are primarily applicable for the POPCORN campaign only, i.e., for an airmass characterized by the composition given in Table 1, and should only be used for air with similar composition.

\section{Conclusion}

For a rural atmosphere we quantified how much the various photolysis processes contribute to the total dependence of $\mathrm{OH}$ on solar UV and demonstrated that $J_{O^{1} D}$ is a suitable measure for that dependence. With (4) we presented a parameterization for the variation in solar UV and atmospheric $\mathrm{NO}_{2}$ concentration, the major influences on $\mathrm{OH}$ in the rural environment considered. It allows to account for that variation and thus opens the way to detect dependences on other, less influential variables. The more detailed analysis of the dependence on $J$ revealed new functional dependences, which contain additional information (such as the indication of the surface source). Such new dependences may prove more dominant in other environments. For instance, the relation between $J_{\mathrm{NO}_{2}}$ and $J_{\mathrm{O}^{1} D}$, which strongly depends on the local stratospheric $\mathrm{O}_{3}$ column, is expected to change with season and latitude. Clearly, the use of (4) is only warranted in environments with $\mathrm{NO}_{\mathrm{x}}$ concentrations sufficiently high to be of influence. In that case, however, the precise measurement of $J_{\mathrm{NO}_{2}}$ is required along with that of $J_{\mathrm{O}^{1} D}$.

\section{References}

Benning, L., and A. Wahner, Measurements of atmospheric formaldehyde (HCHO) and acetaldehyde $\left(\mathrm{CH}_{3} \mathrm{CHO}\right)$ during POPCORN 1994 using 2,4-DNPH coated silica cartriges, J. Atmos. Chem., 31, 105-117, 1998.

DeMore, W., C. Howard, S. Sander, A. Ravishankara, D. Golden, C. Kolb, R. Hampson, M. Molina, and M. Kurylo, Chemical kinetics and photochemical data for use in stratospheric modeling, evaluation number 12 , Tech. Rep. JPL 97-4, Calif. Inst. of Technol., Pasadena, 1997.

Ehhalt, D. H., Gas phase chemistry of the troposphere, in Global Aspects of Atmospheric Chemistry, edited by R. Zellner, chap. 2, pp. 21-110, Steinkopff, Darmstadt, Germany, 1999.

Ehhalt, D., H.-P. Dorn, and D. Poppe, The chemistry of the hydroxyl radical in the troposphere, Proc. $R$. Soc. Edınburgh, 97B, 17-34, 1991.

Eisele, F. L., G. H. Mount, D. Tanner, A. Jefferson, R. Shetter, J. W. Harder, and E. J. Williams, Understanding the production and interconversion of the hydroxyl radical during the Tropospheric OH Photochemistry Experiment, J. Geophys. Res., 102, 6457-6465, 1997. 
Frost, G. J., et al., Photochemical modeling of $\mathrm{OH}$ levels during the First Aerosol Characterization Experiment (ACE 1), J. Geophys. Res., 104, 16,041-16,052, 1999.

Harris, J. W., and H. Stocker, Handbook of Mathematics and Computational Science, Springer-Verlag, New York, 1998.

Holland, F., U. Aschmutat, M. Heßling, A. Hofzumahaus, and D. H. Ehhalt, Highly time resolved measurements of $\mathrm{OH}$ during POPCORN using laser-induced fluorescence spectroscopy, J. Atmos. Chem., 31, 205-225, 1998.

Koppmann, R., C. Plaß-Dülmer, B. Ramacher, J. Rudolph, H. Kunz, D. Melzer, and P. Speth, Measurements of carbon monoxide and nonmethane hydrocarbons during POPCORN, J. Atmos. Chem., 31, 53-72, 1998.

Kraus, A., and A. Hofzumahaus, Field measurements of atmospheric photolysis frequencies for $\mathrm{O}_{3}, \mathrm{NO}_{2}, \mathrm{HCHO}$, $\mathrm{CH}_{3} \mathrm{CHO}, \mathrm{H}_{2} \mathrm{O}_{2}$ and $\mathrm{HONO}$ by $\mathrm{UV}$ spectroradiometry, J. Atmos. Chem., 31, 161-180, 1998.

Rohrer, F., D. Brüning, E. Grobler, M. Weber, D. Ehhalt, R. Neubert, W. Schüßler, and I. Levine, Mixing ratios and photostationary state of $\mathrm{NO}$ and $\mathrm{NO}_{2}$ observed during the POPCORN field campaign at a rural site in Germany, $J$. Atmos. Chem., 31, 119-137, 1998.

Schrimpf, W., K. Linaerts, K. Müller, R. Koppmann, and J. Rudolph, Peroxyacetyl nitrate (PAN) measurements during the POPCORN campaign, J. Atmos. Chem., 31, 139-159, 1998

Sillman, S., J. A. Logan, and S. C. Wofsy, A regional scale model for ozone in the united states with subgrid representation of urban and power plant plumes, J. Geophys. Res., 95, 5731-5748, 1990.

D. H. Ehhalt and F. Rohrer, Forschungszentrum Jülich GmbH, Institut für Atmosphärische Chemie, D-52425 Jülich, Germany. (f.rohrer@fz-juelıch.de)

(Received June 3, 1999; revised September 14, 1999; accepted October 18, 1999.) 